\title{
EFECTO IN VITRO DEL EXTRACTO DE Solanum sessiliflorum “COCONA" SOBRE EL CRECIMIENTO DE Helicobacter pylori
}

\section{In vitro effect of Solanum sessiliflorum “cocona” extract on the growth of Helicobacter pylori}

\author{
María A Pardo Sandoval ${ }^{1}$
}

${ }^{1}$ Facultad de Farmacia y Bioquímica de la Universidad Nacional Mayor de San Marcos. Centro de Análisis Bioquímicos y Clínicos de la Universidad Privada Norberth Wiener

\section{RESUMEN}

El objetivo del presente trabajo fue determinar y comparar el efecto in vitro del extracto de Solanum sessiliflorum "cocona" sobre Helicobacter pylori frente a los antibióticos: amoxicilina, tetraciclina, claritromicina y amikacina. La susceptibilidad para estos antibióticos fue determinada por el método de difusión de discos y el efecto del extracto de cocona sobre Helicobacter pylori por el método de placa vertida. Las cepas de Helicobacter pylori fueron obtenidas de biopsias gástricas y los medios utilizados fueron Columbia blood agar base y Mueller Hinton suplementado con $5 \%$ de sangre de carnero y, para la reactivación de las cepas de Helicobacter pylori, un suplemento específico Dent (Vancomicina 5 mg, trimetropina 2,5 mg, cefsulodina 2,5 mg y anfotericina B 2,5 mg); el ambiente microaerofílico se consiguió empleando OXOID Campy Gen. Los resultados confirman el efecto inhibitorio in vitro del extracto de cocona sobre Helicobacter pylori, siendo superior al de los antibióticos usados.

Palabras clave: Helicobacter pylori, Solanum sessiliflorum, cocona, antibióticos, microaerofília

\section{SUMMARY}

Was determinated that effect of cocona extract against Helicobacter pylori in culture media, as well as, the effects of the following antibiotics: Amoxicyline, Tetracycline, Claritromycine and Amikacine. The susceptibility for these antybiotics was determined by the method of disk diffusion and the effect of cocona extract against Helicobacter pylori by the method of pouring plate. The Helicobacter pylori strains were obtained of gastric biopsies, the media that were used, were Columbia blood base agar and Mueller Hinton supplemented with 5\% sheep blood agar and for reactivating the Helicobacter pylori strains, a specific supplement DENT (Vancomycin $5 \mathrm{mg}$, trimethropine 2,5 $\mathrm{mg}$, cefsulodin 2,5 mg, amphoterecin B 2,5 mg), the microaerofilic environment was obtained by employing OXOID Campy Gen. The results showed that the cocona extract inhibits the growth of Helicobacter pylori and this effect is superior to the ones obtained by the antibiotics that were used .

Key words: Helicobacter pylori, Solanum sessiliflorum, Cocona, antibiotics, microaerofilic.

\section{INTRODUCCIÓN}

$\mathrm{H}$ elicobacter pylori es una bacteria multiflagelada y microaerofílica descubierta por Marshall en 1982; es el agente etiológico de varios trastornos gastrointestinales en el hombre tales como gastritis crónica, úlcera gástrica ${ }^{(1)}$, úlcera duodenal, adenocarcinoma de la parte distal del estómago y linfoma de tejido linfoide asociado a mucosa gástrica. La gastritis puede progresar hacia una gastritis atrófica crónica, que es una lesión posiblemente precursora del cáncer gástrico. El riesgo de desarrollar cáncer se incrementa cuando el intervalo de tiempo de infección es mayor de diez años ${ }^{(2)}$. La Organización Mundial de la Salud lo ha clasificado como carcinógeno tipo I.

Helicobacter pylori vive en la capa de mucus del estómago, donde se encuentra parcialmente protegido del ácido clorhídrico debido a la producción de grandes cantidades de ureasa, la cual al hidrolizar la urea gene- ra amonio que neutraliza el entorno ácido del estómago, protegiéndose aún más del medio externo. Sachs y col. ${ }^{(3)}$ describieron una proteína que la denominaron Urei, encargada de regular la transferencia de úrea del medio externo del estómago hacia el citoplasma del $H$. pylori mediante canales que atraviesan la membrana celular; cuando se incrementa el ácido del estómago, los canales elevan considerablemente la cantidad de úrea que entra al citoplasma del $H$. pylori, con la consiguiente super producción de amonio para neutralizar el periplasma (área entre las membranas externa e interna). En ausencia de la urei, la cantidad de úrea es insuficiente, generándose menos amonio; en consecuencia, al no poder neutralizar su propio periplasma el $H$. pylori se hace vulnerable al $\mathrm{pH}$ del estómago.

Es importante destacar que la infección por $H$. pylori ha sido asociada con riesgo dos veces mayor de padecer enfermedades cardiovasculares independientes de otros factores como hiperlipidemias; no obstan- 
te, existen informes contradictorios, la infección por $H$. pylori se ha relacionado en estudios prospectivos con el infarto del miocardio y con la enfermedad coronaria. Hernández ${ }^{(4)}$, considera hipotéticamente que la modificación del metabolismo lipídico puede contribuir a agravar la situación. Niémela, en Finlandia detectó una asociación entre la presencia de $H$. pylori, una concentración elevada de triglicéridos en suero y una menor concentración de HDL-colesterol.

Con respecto a la terapia a seguir para la erradicación del $H$. pylori, existen diversos esquemas terapéuticos basados en la erradicación de la bacteria a través de la combinación de drogas bacteriostáticas o bactericidas, con los consiguientes efectos adversos, que en la mayoría de los casos no permiten continuar el tratamiento, ocasionando la no erradicación del $H$. pylori; por tanto es considerable la importancia de utilizar nuevas alternativas terapéuticas de erradicación de la bacteria basadas en el empleo de productos naturales, de bajo costo y de mayor grado de satisfacción y conformidad para los pacientes.

El objetivo de esta investigación fue determinar el efecto del extracto de cocona sobre Helicobacter Pylori y compararlo con agentes bacteriostáticos y bactericidas in vitro.

\section{MATERIAL Y MÉTODOS}

\section{Material biológico}

Se emplearon dos cepas de Helicobacter pylori obtenidas de biopsias.

\section{Extracto de cocona}

El extracto puro de cocona fue obtenido del fruto de Solanum sessiliflorum Dunal procedente de Tingo María, Región Huánuco, empleando un licuo-extractor, protegiéndose de la luz durante su manipulación.

\section{Materiales y Reactivos}

Jarra de anaerobiosis, autoclave, medio Mueller Hinton, generadores OXOID Campy Gen, Suplemento Dent, Suplemento sangre de carnero, Blood Agar Base, discos de sensibilidad de amoxicilina, tetraciclina, claritromicina y amikacina.

\section{Procedimiento}

\section{Control de calidad de la sangre y el extracto de} cocona.

Se realizó en: a) Placas Petri que contenían medio Mueller Hinton suplementado con $5 \%$ de sangre de carnero y, b) Placas Petri con medio Mueller
Hinton suplementado con 5\% de sangre de carnero y $1 \mathrm{~mL}$ de extracto de cocona, esparcido con un hisopo en tres direcciones. Las placas se colocaron en la jarra de anaerobiosis, y se incubaron a $37^{\circ} \mathrm{C}$ en atmósfera microareofílica con $85 \% \mathrm{~N}_{2}, 10 \%$ de $\mathrm{CO}_{2}$ y $5 \%$ de $\mathrm{O}_{2}$ durante cinco días.

\section{Reactivación de las cepas de Helicobacter pylori}

Las cepas se sembraron en Blood Agar Base Columbia (OXOID), que contenía $5 \%$ de sangre de carnero y suplemento selectivo Dent (Vancomicina 5,0 $\mathrm{mg}$, cefsulodina $2,5 \mathrm{mg}$, trimetropina $2,5 \mathrm{mg}$ y anfotericina $\mathrm{B} 2,5 \mathrm{mg}$ ). Las placas se colocaron en la jarra de anaerobiosis GasPack 2,5 L y luego se incubaron a 37 ${ }^{\circ} \mathrm{C}$, en atmósfera microaerofílica por cinco días. El cultivo de $H$. pylori fue identificado macro y microscópicamente, y mediante pruebas bioquímicas de oxidasa, catalasa y ureasa.

2.1. Subcultivos del Helicobacter pylori. Los subcultivos de la biomasa del cultivo puro fueron sembrados en un medio no selectivo, en toda la superficie de la placa. Las placas se incubaron a $37^{\circ} \mathrm{C}$ en ambiente microaerofílico durante cinco días; con esto se evitaron posibles contaminaciones.

2.2.1. Determinación de la sensibilidad a los antibióticos ${ }^{(4)}$. El inóculo se preparó en caldo tripticasa de soya (CTS) con el subcultivo de $H$. pylori ajustando la turbidez con el tubo 0,5 de la escala de Mc Farland. (1,5 x $\left.10^{8} \mathrm{UFC} / \mathrm{mL}\right)$. La suspensión de bacterias resultante se hisopó sobre la superficie del agar Mueller Hinton suplementado con 5\% de sangre de carnero y suplemento selectivo Dent por la técnica del tapete, se dejó secar unos minutos y luego se procedió a colocar los discos de antibióticos amoxicilina, tetraciclina, claritromicina y amikacina. Las placas petri fueron llevadas a incubación en ambiente microaerofílico por cinco días.

2.2.2. Determinación de la actividad antimicrobiana del extracto de cocona. Se utilizaron cinco placas con medio Mueller Hinton suplementado con $5 \%$ de sangre de carnero y suplemento selectivo Dent en las que primero se depositaron, con hisopos estériles, por la técnica del tapete, los inóculos de Helicobacter pylori suspendidos en cantidad suficiente de suero fisiológico para obtener una turbidez equivalente al o, 5 en la escala de Mc Farland. Luego se esparcieron en tres direcciones en la superficie de la placa, se dejó secar y seguidamente se depositaron discos de papel de filtro de $6 \mathrm{~mm}$ de diámetro conteniendo o,1; o,2; o,3; o, 4 y o, $5 \mathrm{~mL}$ de extracto de 
cocona. Las placas se incubaron a $37^{\circ} \mathrm{C}$ en atmósfera microareofílica por cinco días.

\section{RESULTADOS}

En las placas donde se realizó el control de calidad de los medios de cultivo y del extracto de cocona no se registró crecimiento de microorganismos, lo que nos confirmó que tanto la sangre de carnero como el extracto de cocona no estaban contaminados.

La reactivación de las cepas de Helicobacter pylori fue positiva, sólo en una de las cepas fue imposible la reactivación. Las colonias de Helicobacter pylori obtenidas fueron identificadas mediante coloración Gram, prueba oxidasa, catalasa y ureasa, siendo positivas a todas ellas.

La determinación de la sensibilidad del H. pylori a los antibióticos amoxicilina, tetraciclina, claritromicina, y amikacina realizada por la técnica del tapete, se muestran en la tabla 1.

Tabla 1. Sensibilidad de los antibióticos

\begin{tabular}{cc}
\hline Antibiótico & Sensible \\
\hline Amoxicilina & $>30 \mathrm{~mm}$ \\
Tetraciclina & $>30 \mathrm{~mm}$ \\
Claritromicina & $>25 \mathrm{~mm}$ \\
Amikacina & $>25 \mathrm{~mm}$ \\
\hline
\end{tabular}

Con respecto a los resultados obtenidos acerca de la actividad antimicrobiana del extracto de cocona, encontramos $100 \%$ de inhibición del $H$. pylori, siendo importante destacar que la prueba se corrió simultáneamente en cinco placas y por quintuplicado.

\section{DISCUSIÓN}

La infección por $H$. pylori es difícil de erradicar debido al $\mathrm{pH}$ ácido del estómago y a la localización extracelular de la bacteria; no obstante, en algunos pacientes se localiza profundamente insertándose en la matriz del mucus que reviste el epitelio gástrico ${ }^{(5,6)}$, donde los antibióticos no se distribuyen adecuadamente o el $\mathrm{pH}$ ácido los inactiva ${ }^{(7)}$. Para erradicarlo, se han aplicado diferentes esquemas de tratamiento, en unos casos asociaciones de medicamentos, que incluyen fármacos bloqueadores $\mathrm{H}_{2}$ tales como cimetidina o inhibidores de la bomba de protones como el omeprazol ${ }^{(8)}$, conjuntamente con antibióticos, con el fin de conseguir una mayor efectividad ${ }^{(9)}$. Para este propósito, los antibióticos más usados son: claritromicina, que en algunos casos presenta resistencia microbiana ${ }^{(10)}$; amoxicilina a dosis baja, que muestra mayor efectivi- dad, y tetraciclina ${ }^{(11)}$ a mayores dosis.

Desde el año 1983 en que Warren y Marshall (12) descubrieran al Helicobacter pylori, como responsable de la inflamación gástrica y de la úlcera, se han realizado numerosas investigaciones empleando plantas medicinales, en unos casos extracto de canela, en otros el ajo bajo la forma de extracto, aceite ó polvo. Los investigadores Jones y Tamariz ${ }^{(13)}$ emplearon sangre de grado obtenida del Croton lechleri, logrando un efecto inhibidor sobre $H$. pylori. Lengsfeld ${ }^{(14)}$, utilizó el extracto seco del zumo del Ribes nigrum, con lo que se consiguió bloquear los receptores de la mucosa gástrica impidiendo con ello la adhesión del Helicobacter pylori a la mucosa.

El incremento de cepas de $H$. pylori resistentes a los antibióticos empleados en su tratamiento, el elevado costo de estos tratamientos y los excelentes resultados obtenidos por Zhang L. y Shmuely H. ${ }^{(15,16)}$ al utilizar el extracto del Vaccinium erythrocarpum "arándano", nos motivaron al empleo de extractos de plantas medicinales volcando nuestra atención específicamente al extracto puro de cocona para erradicar $H$. pylori, bacteria que muestra una gran variabilidad fenotípica y genética.

En el presente estudio utilizamos cuatro antibióticos de comparación: amoxicilina, tetraciclina, claritromicina y amikacina. En la bibliografía consultada no se ha encontrado referencia de este último; sin embargo, consideramos conveniente utilizarlo como posible alternativa antibacteriana. Los cuatro antibióticos mostraron buena actividad sobre $H$. pylori, obteniendo un halo de inhibición promedio de $27 \mathrm{~mm}$, superior al hallado por otros investigadores.

El extracto de cocona puro, utilizado a diversas concentraciones desde 0,1 a o,5 mL, mostró una gran actividad inhibiendo el crecimiento de $H$. pylori en un $100 \%$, lo que consideramos como un hallazgo valioso, que amerita la realización de una posterior investigación in vivo; a fin de determinar la efectividad del extracto de cocona en el tratamiento de las infecciones humanas por $H$. pylori.

\section{CONCLUSIONES}

El extracto de cocona inhibe el crecimiento in vitro de Helicobacter pylori en un $100 \%$.

El efecto inhibitorio del extracto de cocona es superior al de los antibióticos amoxicilina, tetraciclina, claritromicina, y amikacina. 


\section{REFERENCIAS BIBLIOGRÁFICAS}

1. Blaser M, Atherton J. Helicobacter pylori persistence: biology and disease. J Clin Invest 2004; 113(3): 321-33.

2. Chan FK, Leung WK. Peptic-ulcer disease. Lancet 2002; 360: 933-41.

3. Weeks et al. A H+-Gated Urea Channel: The Link Between Helicobacter pylori Urease and Gastric Colonization. Science 2000 Jan 21; 287(5452): 482-5.

4. McNulty C, PHLS Helicobacter Working Group. Helicobacter pylori susceptibility testing by disc diffusion. J Antimicrob Chemother 2002; 49(4): 601-9.

5. Kazi JL, Sinniah R, Zaman ML, Ng ML(verificar), Jafarey NA, Alam SM et al. Ultrastructural study of Helicobacter pylori-associated gastritis. J Pathol 1990; 161(1): 65-70.

6. Yoshiyama $\mathrm{H}$, Nakazawa $\mathrm{T}$. Unique mechanism of Helicobacter pylori for colonizing the gastric mucus. Microbes Infect 2000; 2(1): 55-60.

7. Mégraud F. Adjuvant therapy for Helicobacter pylori eradication: Role of lansoprazole shown in vitro. J Clin Gastroenterol 1995; 20 supl 1: 22-7.

8. Páez-Sáenz R, Avendaño-Alvarado G, Ávalos- Giugliarelli A, Barahona-García R, Ramírez V et al. Erradicación de Helicobacter pylori mediante triple terapia (amoxicilina, claritromicina y omeprazol) en pacientes del Hospital Rafael Ángel Calderón Guardia Salas-Aguilar. Acta Med Costarric 2003; 45(2):57-61.

9. Calvet X, Garcia N, López T, Gisbert JP, Gene E, Roque M. A meta analysis of short versus therapy with a proton pump inhibitor, clarithromicin and either metronidazole or amoxycilin for treating Helicobacter pylori infection. Aliment Pharmacol Ther 2000; 14(5): 603-9.

10. Harris A, Misiewicz JJ. Management of Helicobacter pylori infection. BMJ 2001; 323: 1047-9.

11. Fariña N, Kasamatsu E, Samudio M, Morán M, Sanabria R, Laspina F. Susceptibilidad a antibióticos de cepas paraguayas de Helicobacter pylori aisladas de pacientes con enfermedad gastro-duodenal. Rev Med Chile 2007; 135(8): 1009-14.

12. Marshall BJ, Warren JR. Unidentified curved bacilli in the stomach of patients with gastritis and peptic ulceration. Lancet 1984; 323(8390): 1311-5.

13. Jones K, Tamariz H. Review of Sangre de Drago (Croton lechleri). A South American tree Sap in the treatment of diarrhea, inflammation, insect bites, viral infections, wounds: traditional uses to clinical research. Alternative Complementary Med 2003; 99(6): 877-96.

14. Lengsfeld C. High molecular weight polysaccharides from black currant seeds inhibit adhesion of Helicobacter pylori to human gastric mucosa. Planta Med 2004 Jul; 70(7): 620-6

15. Zhang L, Ma J, Pan K. Efficacy of cranberry juice on Helicobacter pylori infection: a doubled blind, randomized placebo - controlled trial. Helicobacter 2005; 10(2): 139-45.

16. Shmuely H, Yahav J, Samra Z. Effect of cranberry juice on eradication of Helicobacter pylori in patients treated with antibiotics and a proton pump inhibitor. Mol Nutr Food Res 2007; 51(6): 746-51

Manuscrito recibido el: 23/02/2010

Aceptado para su publicación el: 11/o8/2010

\section{Correspondencia:}

Nombre: Anselma Pardo Sandoval

Dirección: Av. Arequipa 440 - Lima o1 - Perú.

e-mail: mpardo@wienergroup.com 